\title{
UNDERSTANDING INTERSECTING PROCESSES
}

\author{
COMPLEX ECOLOGIES OF DIVERSITY, \\ IDENTITY, TEACHING, AND LEARNING
}

\author{
Kristen A. Renn \\ Michigan State University
}

Teaching and learning take place within complex interactions of students, instructors, and environments. Within these environments, diversity and identity play a role in how individuals experience the learning context. This chapter describes an ecological model (Bronfenbrenner, 1979, 1993) and uses it to analyze how diversity and identities interact with the processes of teaching and learning. Examples from research with students of color and lesbian, gay, bisexual, and transgender students illustrate barriers to learning and opportunities to use diverse identities to engage students more effectively. The chapter ends with recommendations for improving the classroom climate for diverse learners.

o

Eleanor is a sophomore taking beginning Spanish. The professor believes in integrating student experiences into language learning. Students create scrapbooks of their families and friends and then learn vocabulary related to the images. Students begin dialogues: "Esta es mi madre." "Es que tu padre?" "Sí, estos dos son mis padres." This is my mother. Is this your father? Yes, these two are my parents. And then the instructor continues 
to question Eleanor. "How can these be your parents?" he says in Spanish. "They can't be your parents. They don't look like you." Eleanor barely understands the barrage of Spanish and is defenseless to respond. More than that, though, she is stunned by the accusation that her white mother and black father are not her parents.

Hoping to engage her first-year seminar in a debate about global climate change, an instructor goes for an easy division of students into teams. "Okay, everyone, we'll have guys on this side and ladies over here." For most students, the instructions are clear and simple. But for Caiden, who has been exploring gender identity, they are more complicated. Caiden identifies with neither the hypermasculine "guy" code of college life nor with the hyperfeminine "ladies." While everyone else shuffles to the "correct" side of the room, Caiden wonders what will happen if other students sense the hesitation or notice that Caiden does not belong on the side to which Caiden ultimately goes.

Jon's professor has invited students in an interdisciplinary seminar to write research papers on any topic they choose. Jon wants to write about the intersection of scientific research, activism, and politics related to the AIDS crisis. Jon identifies as gay, though he has not come out publicly at his small Christian college. He is worried that his professor will (correctly) assume that his interest in the history and politics of HIV research stems from his identity as a gay man. He is shocked when he gets back his topic statement from the professor with the comment, "This sounds terrific! I've got friends at the Centers for Disease Control who can help with this. I'll put you in touch." Working on the paper, Jon makes important connections with openly gay and lesbian scientists, one of whom hires him to work in her laboratory after graduation.

These three scenarios, all from participants in studies of mixed-race college students and lesbian, gay, bisexual, and transgender (LGBT) students (Renn, 2004, 2007), demonstrate the ways that identities enter the complex interactions that make up the processes of teaching and learning. Eleanor's and Caiden's experiences of alienation in the classroom occurred even when faculty were trying to use inclusive teaching strategies. Viewing the complexity of diversity, identities, teaching, and learning through a human or developmental ecology lens provides insight into the interactions among them and suggests ways to improve student learning.

\section{Ecologies of Teaching and Learning}

Human and developmental ecology theories parallel biological concepts of ecology in ways that are useful for examining complex person-environment interactions, such as those that occur in the teaching 
and learning processes. Four key concepts in ecology relate to teaching and learning in higher education. First, students and instructors are organisms operating within dynamic environments. These environments are natural (geography, climate, weather) and human-made (architecture, curriculum, organizations) (Moos, 1973; Strange \& Banning, 2001). Second, organisms influence environments, and environments influence organisms. Specifically, students influence learning environments, and learning environments influence students (Bronfenbrenner, 1979; Strange \& Banning, 2001). Third, different environmental niches favor organisms, including students, with particular traits (Renn \& Arnold, 2003). One student might thrive at a community college, another at a liberal arts college, and a third at a comprehensive university. Finally, when an organism and its environment do not match well, one or both must adapt or be adapted lest the organism extinguish. In colleges and universities "extinction" means that students leave a course, a major, or an institution. Or a student may remain in place, extinguishing his or her learning. A learning ecology lens forms the foundation for understanding how educational environments influence individuals and outcomes.

Urie Bronfenbrenner's developmental ecology model provides a blueprint for this foundation (Bronfenbrenner, 1979, 1993). Bronfenbrenner created the model out of his work with young children. Renn and Arnold (2003) adapted it specifically for use in higher education. It has four key elements: person, process, context, and time. (Bronfenbrenner typically ordered them process-person-context-time; I present person first.)

\section{Person}

The person element of the model refers to the demographic and personal characteristics of the learner, including heritage, demographics, talents, and habits of mind. It also includes "developmentally instigative characteristics" (Bronfenbrenner, 1993, p. 11) that influence the individual's interactions with the environment.

Bronfenbrenner described four developmentally instigative characteristics. First are characteristics that invite or inhibit responses from the environment. For college students interacting with faculty, these characteristics might include physical appearance, confidence, manners, and language. The second group relates to selective responsivity, or the ways that students explore and react to their surroundings. Some students, for example, may seek out faculty in office hours and respond quickly to e-mail messages from a professor, while others do not. Structuring proclivities are the third category of characteristics. These are the ways that students engage in increasingly complex activities such as more difficult courses, 
independent research, and leadership activities, which are keys to their development and learning. The fourth category is directive beliefs, relating to the ways that individuals understand agency in relationship to the environment. Some students are active creators of their college experience, and others are more passive.

As a group, the developmentally instigative characteristics shape how an individual will experience the learning environment and how faculty and other students will react to him or her. These characteristics help explain why some students may seem easy to mentor, enjoyable to teach, and engaging to advise, while other students seem harder or less rewarding to engage. To illustrate, I will use a model student, Maria, whose story is a composite drawn from my research with students of color (Renn, 2004).

Maria is a first-generation Latina student who excelled in math and science in high school. She seeks out new academic challenges but is shy and holds back from social interactions with peers. In her first year, she had a campus job washing beakers for the chemistry department, and she has since been promoted to supervising other students and setting up equipment for multiple lab sections. The white male faculty member for whom Maria works nominated her for a summer research fellowship and offered to introduce her to faculty and graduate students in the department, including women and people of color. Maria likes being at the university but does not have many friends here. She lives in an apartment with a high school friend and prefers to go home on weekends to be with her family. All of these characteristics-demographic, identities, and tendency to seek some challenges while avoiding others-make up the person who is Maria.

Maria's story begins to show how the ecology model plays out in terms of ecological niches. She thrives in courses and her job in the lab because she seeks out challenges and demonstrates her maturity and responsibility. She has successfully integrated into her academic life and has attracted an academic mentor. She is surviving, though not thriving, in social niches, where her shyness holds her back. She is not very likely to attract a friendship group to provide additional social, academic, and personal support for her college journey.

The ecology model takes a value-neutral stance on niches, though educators may have ideas about which are more important for student success. Maria's differential integration into the overall college environment illustrates the concept of niches and personal characteristics. Some characteristics are highly favored in some niches (responsibility is highly valued in the work setting) but may not get students far in others (workrelated responsibility is not always valued in the formation of friendship 
groups, for example). An outgoing student who seeks novel social situations might integrate easily into the peer culture but could be less successful in attracting an intellectual mentor.

\section{Process}

These interactions with other people and with the environment are the second part of the Bronfenbrenner model: process. To promote learning and development, interactions must be of increasing complexity and adequately supported (Renn \& Arnold, 2003). Maria's inclination to challenge herself in more difficult course work promotes greater learning than if she plateaued with midrange courses. Similarly, the increased responsibility she assumes in her job provides opportunities for increased complexity of human interaction. Her so-called soft skills may be challenged, and she will have to learn more complex ways of interacting. Her decision to go home to her family and friends on weekends, however, does not necessarily call for increasing complexity, so she may not grow as much in those interactions. The process part of the model calls for increasing complexity and challenge in proximal settings, a familiar concept in constructivist learning theory (see King, 2009).

\section{Context}

Context is where learning and development occurs, and for college students, the settings are many and diverse. Bronfenbrenner $(1979,1993)$ named four levels of the context (see Figure 17.1). Microsystems are the immediate settings in which the individual interacts with the environment. Maria's microsystems include courses and lab sections, her campus job, her apartment mate, and family and friends at home. For other students, there might be a sports team, sorority or fraternity, Reserve Officer Training Corps, performing arts group, or faith community.

Interactions between and across microsystems create the mesosystem: a web of interactions that set a context of peer culture and learning expectations. These may be very consonant mesosystems, where a uniform message is reinforced, or dissonant mesosystems, in which the learner has to manage competing messages (as when a student-athlete gets one message from teammates and a different message from his instructors). As with the notion of niches, the model is neutral as to whether consonant or dissonant is better for learning. I maintain that dissonance does not stifle learning; rather, it challenges the learner in different ways. 
Figure I 7.I. Ecology of Teaching and Learning.

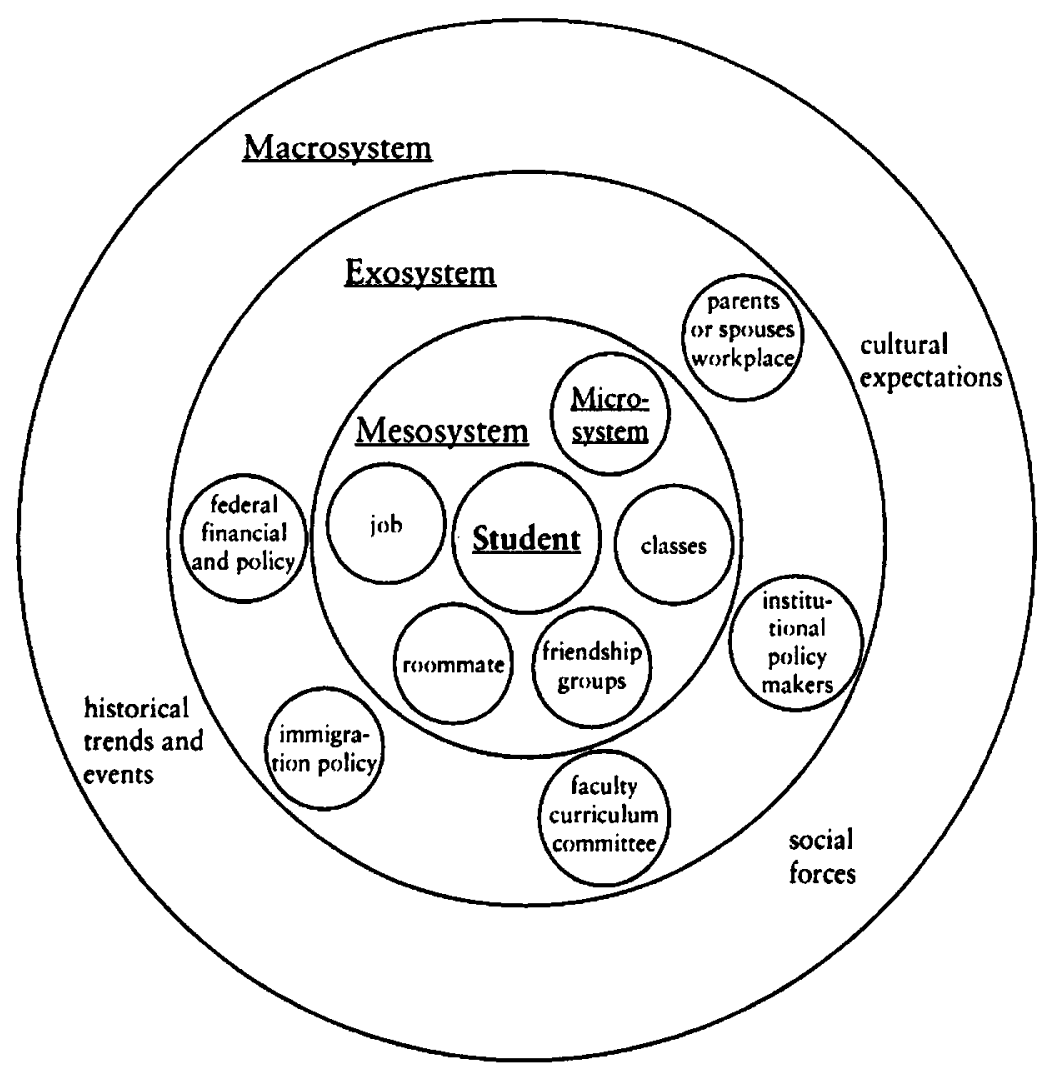

Source: Renn o Arnold. (2003). Reprinted by permission of The Obio State University Press.

The contexts in which teaching and learning occur are influenced by factors outside the immediate actors of faculty and students. Bronfenbrenner $(1979,1993)$ called these factors the exosystems: systems that affect development and learning but do not contain the individual. Maria's parents' workplaces are good examples. Maria is not in these contexts, but if one of her parents is laid off or gets a raise, it is likely to have an impact on Maria. She may have to work more, or she may be able to afford to study abroad. Faculty decisions about curriculum are exosystems because they do not contain the student but influence her or him; financial aid policy and immigration laws offer additional examples. 
Exosystems are important contexts to consider, even though they are not directly in front of the learner.

Finally in the context element, the macrosystem contains the sociohistorical and cultural factors that influence learning. The fact that a woman is in science or a Latina is in chemistry is possible because of changes in the macrosystem over time that open society to diverse learners. Cultural values about family also influence Maria's educational decisions and options. The macrosystem represents the big picture context that influences learning.

\section{Time}

The last element of the model is time. Time accounts for large-scale historical events, such as the terrorist attacks on September 11, 2001, or the election of the first man of color as U.S. president, that influence individuals. Time also includes more personal events, like the timing of a sibling's birth or parents' divorce in the life span of the individual, that make a difference in his or her learning opportunities.

\section{Diversity and Identity}

With the four elements (person-process-context-time) of the ecology model in place, I turn now to the question of diversity and identity in the ecology of teaching and learning. Like other students, Maria brings her characteristics and characteristic ways of being in the world into the college context. Some niches in the context favor her characteristics, and others do not. Maria can adapt to fit the latter niches, or she can leave these niches. But ecology is not one-way: Maria also has influence on her environment. The way she interacts in class shapes the environment for faculty and other students, just as the way she does her work in the chemistry lab shapes that environment for others. The very fact that Maria is a visible Latina major in the sciences may alter how some younger students perceive their options and opportunities. The ecosystem is a dynamic place of mutual influence, construction, and reconstruction.

For instructors, this dynamic learning ecosystem is made more complex when dozens, if not hundreds, of individual students come together in the microsystem of a single class. There are as many different learning ecologies in a class as there are students. Faculty also bring their own ecosystems to the context. A class represents a shared microsystem for each student and instructor, but it is only one of many microsystems in each person's life. The ecological perspective may be useful in thinking 
about individuals, but it quickly seems overwhelming when considering using it to improve teaching and learning on the scale of real institutions. The model also offers a potential solution to the complexity: focusing on creating microsystems that favor, or at least tolerate, a wide range of characteristics that learners bring with them so that Eleanor, Caiden, Jon, or Maria can thrive. Creating such microsystems involves attending to the vital topics of diversity and identities, which are inherently part of the person element of the ecology model.

Campus diversity talk revolves around a common set of terms, with limited variation across institutions: sex, gender, race, ethnicity, sexual orientation, ability, social class, religion, and faith tradition. Less often considered are diversities of student status (part time or full time, straight from high school or nontraditional). Other groups include returning war veterans; students from urban, suburban, and rural areas; and in-state, out-of-state, and international students. For many people, these categories describe not just demographics but also identities.

Students exist within complex ecologies of interactions, identities, and development. The examples of Eleanor, Caiden, Jon, and Maria show how identities come with students into different microsystems, or proximal processes, and have the ability to enhance or erode the quality of learning that takes place. These examples are drawn from race, gender, and sexual orientation and point to the ways that identities can be felt, seen, and ascribed to others. Visible differences-skin color, a wheelchair, a veiled head, a gold cross necklace, a military tattoo-may indicate something about students, but it is unwise to assume too much about an individual's identity based on what is observable. Students may use clothing, jewelry, body art, or other means to signal their identities, but they may not identify strongly with the categories they seem to be displaying. There are also some identities that are not visible and are difficult to signal. Students may reveal these identities in a reflection paper, a class project, a conversation, or a Facebook profile.

A well-developed body of literature from psychology and sociology describes how individuals grow into different identities. Some of this research has made its way into the literature on college student development (see Torres, Jones, \& Renn, 2009). For full-time students coming directly after high school, college can be a rich environment in which to explore identities. Students may encounter peers who are different, live in residence halls with people unlike those they have met before, and be on sports teams and student government with unfamiliar people. For adult students, commuters, and part-time students, the opportunities for interaction with diverse others on campus may be more limited. Where 
difference is nearly unavoidable, however, is in the learning context of classrooms, labs, and online courses. These are contexts in which to engage productively the intersecting processes of diversity, identity, teaching, and learning.

\section{Barriers in the Ecosystem}

Intersections in the teaching and learning ecology pose potential barriers to teaching and learning and also open opportunities that can be leveraged to increase learning. Barriers include obvious instances of discrimination and overt statements that seek to exclude or demean particular groups. It is increasingly rare in classrooms to hear overt racial slurs or deliberate put-downs of women. But the report 2010 State of Higher Education for LGBT People (Rankin, Weber, Blumenfeld, \& Frazer, 2010) showed that classrooms are commonly the site of verbal harassment or bullying of LGBT students. Student veterans report that some faculty and classmates conflate criticisms of war with criticisms of soldiers (Phillips, 2007), and students from poor families may be exposed to uninformed comments about "lazy" welfare recipients (Aries, 2008). Immigrant students and children of immigrants are at risk for hearing insensitive comments, which they may endure silently in a classroom where they keep their identity to themselves (see Schwartz, Donovan, \& Guido-DiBrito, 2009). Some students' deeply held identities conflict with other students' identities: the classic example might be a religious fundamentalist and an LGBT student who has had a negative experience with organized religion. A lot can happen in a classroom that falls into a category I describe as outright hostility or an unwelcome climate. It is not hard to imagine how these statements and actions could interfere with the learning process.

As instructors, we have a duty to deal with these incidents when we are witnesses or when students tell us about them. Clear statements about the value of free speech in the context of respect for others, whether in the syllabus or given verbally, set a tone. Addressing instances immediately, either in class or privately afterward, also interrupts a hostile climate. Instructors themselves, of course, should refrain from consciously or thoughtlessly singling out groups for scorn. We must also educate and supervise teaching assistants appropriately.

Beyond outright hostility, there are also what Solórzano, Ceja, and Yosso (2000) called microaggressions-the more subtle everyday messages that accumulate in the micro- and mesosystems. Microaggressions include lowering expectations, tokenizing individuals, ignoring obvious discrimination, 
and tolerating or telling offensive jokes. They also include persistently surveilling students from one group, assuming that someone does not speak English, being surprised to meet someone from $\mathrm{X}$ background in $\mathrm{Y}$ major, refusing or forgetting to refer to a transgender student with the chosen pronoun, mixing up the names of the only two black or Asian or Native or fernale students in the class, or using readings that sustain stereotypes (for example, a textbook in which all nurses are female and all doctors are male). These examples cover a range that some people would classify as microaggressions and others as outright discrimination. My point is not to create a taxonomy, but to note the myriad everyday actions, images, and statements that batter against identities, and some of them happen in teaching and learning settings.

Faculty participate in and perpetuate some of these microaggressions, even when they think they are being progressive and inclusive in their teaching practices. Caiden's instructor was not trying to make a statement about a gender binary: she was trying to engage students in active learning and quickly divide students into groups. In all likelihood, she never knew the dilemma she created for Caiden and potentially others. Caiden's instructor could have accomplished her aims by using a more identityneutral but equally quick scheme, like dividing by odd and even phone numbers.

The nature of teaching and learning ecologies means that there are multiple, intersecting ways to commit outright hostile acts and microaggressions. Indeed, active teaching and learning may be even riskier than lecturing from the textbook. The more interaction there is, the more the microsystems rub up against each other; the more students and instructors interact with one another in learning settings, the more likely it is that we will bump into identities in ways that may not be comfortable or welcoming. Eleanor's professor appeared to be welcoming students' families, and inherently their identities, into the learning process with the scrapbook assignment but was unprepared for the diversity of families that might come to class. He was not wrong to try to connect with students, but his limited sense of what families look like got in the way.

\section{Opportunities in the Ecosystem}

Just as there are risks of discrimination and microaggressions related to identities, there are opportunities to use identities to enhance learning through curriculum, assignments, classroom interactions, and out-of-class interactions. The positive response and follow-up Jon got 
from his professor is an example. I focus in this section on the ways that viewing students and diversity through an ecological lens may help promote learning.

Much of what people think of when they consider college teaching falls into the microsystem level of analysis: how to interact directly with students in the human-built context of classroom and online learning, lab sections, out-of-class interactions, and phone, text, and e-mail communication. Instructors signal through their words and actions the ways in which they are open to and affirming of diverse identities and the ways that they are, sometimes unconsciously, closed to and unwelcoming of some identities in their teaching and learning niches. Course readings, examples used in class to set up a math or science problem, methods for dividing students for group work: all of these are opportunities in the teaching ecology to create hospitable niches for diverse students to learn.

Microsystem interactions with students also become part of the mesosystem contexts of their lives. Here is where faculty can make a difference that extends beyond the immediate, proximal processes. In creating a space in which students can explore and experience diverse identities, faculty may extend an influence beyond the immediate academic interaction. The message, "You're okay here. Bring your whole self," may provide a refuge for a student whose other microsystems are sending a different message. Feeling safe to be who he or she is may be a buffer in an otherwise chilly context-a haven from dismissive or hostile attitudes that pervade other microsystems. For a student already in an overall supportive system of relationships and contexts, the "you're okay here" message may reinforce that support and signal that diversity is valuable and interesting. The message may be that one does not have to leave identity at the door to be an engineer or historian or lawyer; in fact, one may be a better engineer, historian, or lawyer by bringing one's identity and diversity to the table.

Faculty can create supportive and buffering niches by avoiding microaggressions, interrupting those that they witness, and thinking about how people from diverse identities will experience their invitation to bring identities into the learning process. Consider Eleanor's and Caiden's instructors' lack of understanding of students who identify outside racial categories and gender binaries, Jon's professor's support for research, and Maria's mentor in the chemistry lab. Throughout my data collection with LGBT and mixed-race students (see Renn, 2004, 2007), I have heard from students for whom one class, one professor, one assignment created breathing room to explore and express identity. I have also heard about 
the pervasive microaggressions that create a mesosystem that silences and makes identities invisible or unacceptable. Table 17.1 offers examples of positive and negative identity-based interactions between faculty and students in the micro- and mesosystems.

Faculty and faculty developers also play roles at the exosystem level in which they can enact policies, curricula, and programs that take advantage of identities and diversity to create enhanced learning ecologies for all students. Abundant research (Laird, Engberg, \& Hurtado, 2005; Umbach \& Kuh, 2006) indicates that so-called diversity requirements lead all students to have more civically engaged attitudes and to interact

Table 17.1. Examples of Negative and Positive Faculty Interactions with Student Diversity.

\section{Discrimination and Microaggressions}

Instructor makes derogatory comments about an identity group or ignores such comments from students

Instructor includes biased or negatively stereotyped course materials (readings, media)

Instructor acts on the assumption that there are no invisible students and that everyone identifies the way he or she "looks" to others

Instructor asks students to speak for their group

Instructor discourages students from pursuing research or readings on identity-related topics

Instructor limits mentoring to students from groups historically well represented in his or her academic discipline and from groups similar to the instructor's own
Passive and Active Support

Instructor publicly addresses negative comments, sets standards for civil discourse, and openly welcomes diverse identities

Instructor includes positive portrayals of different identity groups in course materials (readings, media)

Instructor expects that there are invisible differences among students and that those differences may make some students feel less welcome in the classroom; instructor makes clear to all students that he or she welcomes this unseen diversity and expects everyone to be respectful of it

Instructor invites all students to respond

Instructor supports students in researching identity-related topics

Instructor seeks out mentees from underrepresented groups; when mentoring students with identities different from their own, instructors use additional resources to provide role models and networks 
with people who are different from themselves. Diversity requirements are most often developed and implemented in students' exosystems.

Another exosystem factor that has a trickle-down effect for students is the hiring, promotion, and tenure process. Attention to hiring diverse faculty creates opportunities for underrepresented students to see themselves in the faculty and for majority students to learn from and with people who are different from themselves. At a minimum, it is possible to prioritize hiring colleagues of any background who are committed to creating teaching and learning ecologies where all students can thrive. Faculty and organizational developers have an opportunity to bring attention to how decisions made in the exosystem of hiring, promotion, and tenure penetrate student learning experiences.

Finally, at the macrosystem level, faculty and faculty developers participate in the same larger sociocultural and historical context as do students. Students and faculty are immersed in a post-9/11 culture, and in the next decade most traditional-age students will have grown up predominantly or exclusively post-9/11. In Texas, California, and Michigan, they will not have known affirmative action in college admissions. Immigration and gay rights (military service, employment nondiscrimination, marriage equality) are critically important to individuals and are touchstones for divisive arguments. Student and faculty lives are saturated with technology and mobile connectivity. Acknowledging this larger context is critically important for instructors in creating learning ecologies where diverse students can thrive.

I do not believe that faculty can or should shelter students from the broader context, but I do believe that we have a duty to account for this larger context when we participate in learning organizations-our universities-that do not yet provide equitable access and opportunities.

\section{Conclusion}

My goal in presenting the ecology model is to provide a way to think about leveraging the power of the ecosystem to enhance teaching and learning through attention to diversity and identities. An ecosystem's frame can be useful in thinking about how instructors fit into the individual and collective learning ecologies of students and the ways that students from all backgrounds and identities bring assets and liabilities to the learning process. Identities seen and unseen, formed and forming, fluid and firmly held are at the core of individual student and faculty experiences, and ecologies challenge us to take them as seriously as we take our subject matter and other elements of our pedagogy. The stakes 
for teaching and learning are high. Eleanor, Caiden, Jon, and all the Marias, real and composite, are depending on us.

\section{REFERENCES}

Aries, E. (2008). Race and class matters at an elite college. Philadelphia, PA: Temple University Press.

Bronfenbrenner, U. (1979). The ecology of human development: Experiments by nature and design. Cambridge, MA: Harvard University Press.

Bronfenbrenner, U. (1993). The ecology of cognitive development: Research models and fugitive findings. In R. H. Wozniak \& K. W. Fischer (Eds.), Development in context: Acting and thinking in specific environments (pp. 3-44). Mahwah, NJ: Erlbaum.

King, P. M. (2009). Principles of development and developmental change underlying theories of cognitive and moral development. Journal of College Student Development, 50(6), 597-620.

Laird, T.F.N., Engberg, M. E., \& Hurtado, S. (2005). Modeling accentuation effects: Enrolling in a diversity course and the importance of social action engagement. Journal of Higher Education, 76(4), 448-476.

Moos, R. (1973). Conceptualizations of human environments. American Psychologist, 28, 652-665.

Phillips, S. (2007, February 16). Top guns on campus. Times Higher Education. Retrieved from http://www.timeshighereducation.co.uk/story.asp?story Code $=207842 \&$ sectioncode $=26$

Rankin, S., Weber, G., Blumenfeld, W., \& Frazer, S. (2010). 2010 state of higher education for leshian, gay, bisexual and transyender people. Charlotte, NC: Campus Pride.

Renn, K. A. (2004). Mixed race college students: The ecology of race, identity, and community. Albany: State University of New York Press.

Renn, K. A. (2007). LGBT student leaders and queer activists: Identities of lesbian, gay, bisexual, transgender, and queer-identified college student leaders and activists. Journal of College Student Development, 48(3), 311-330.

Renn, K. A., \& Arnold, K. D. (2003). Reconceptualizing research on peer culture. Journal of Higher Education, 74, 261-291.

Schwartz, J. L., Donovan, J., \& Guido-DiBrito, F. (2009). Stories of social class: Self-identified Mexican male college students crack the silence. Journal of College Student Development, 50(1), 50-66.

Solórzano, D., Ceja, M., \& Yosso, T. (2000). Critical race theory, racial microaggessions, and campus racial climate: The experiences of African American college students. Journal of Negro Education 69(1/2), 60-73. 
Strange, C. C., \& Banning, J. H. (2001). Educating by design: Creating campus learning environments that work. San Francisco, CA: Jossey-Bass.

Torres, V., Jones, S. R., \& Renn, K. A. (2009). Identity development theories in student affairs: Origins, current status, and new approaches. Journal of College Student Development, 50(6), 577-596.

Umbach, P. D., \& Kuh, G. D. (2006). Student experiences with diversity at liberal arts colleges: Another claim for distinctiveness. Journal of Higher Education, 77(1), 169-192. 